\title{
Memorializing Queers / Queering Remembrances: Encounters with Loss and the Problematics of Identity
}

\section{SHARON ROSENBERG}

Sharon Rosenberg is Assistant Professor in the Theory / Culture focus of the Department of Sociology at the University of Alberta. She is co-editor, with Roger I. Simon and Claudia Eppert of Between Hope and Despair: Pedagogy and the Remembrance of Historical Trauma (2000) and co-author, with Ann Braithwaite, Susanne Luhmann and Susan Heald of Troubling Women's Studies: Pasts, Presents and Possibilities (2004).

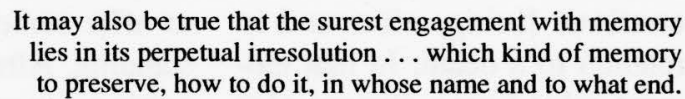
- James Young (21)

\begin{abstract}
s I deliberate on how to introduce this special issue of torquere, I have in mind two moments, both from the last year, the 1 juxtaposition of which animates something for me, and I hope for you, of what is at stake in memorializing queers and queering remembrances.
\end{abstract}

I am standing at the Vancouver AIDS Memorial with my lover, on a few days' break from winter and the academic term. As we are carefully reading the inscription and taking in the listing of names, two runners, a man and a woman, jog by. They slow down; she touches one of
I am teaching a fourthyear undergraduate course on queer theorizing. About halfway through the course we are doing a section on AIDS memorializing, reading about the AIDS Quilt, the politics and problematics of representation, and viewing films that take up these 


\section{$2 /$ Rosenberg}

the names as she passes. A simple gesture, perhaps, but one that strikes me then and still as marking something crucial about why memorials matter. What I read in her fleeting touch of a name cut into steel is an expression of remembering as a practice of living; that is, while the memorial (as all monuments of its kind) risks becoming read over time as static and of little note to those who pass by, it can also work as a touchstone, an address to the living to remember as part of what it means to continue living, after and in relation to a death. In that moment, what I got a glimpse of (I think; after all, this is my reading) was something of how the individual dead can be kept ... not so much "alive" but as a presence. On these terms, the individual dead are a mattering, part of the dailyness of living rather than to be conjured simply on special occasions (anniversaries, birthdays, at vigils for other dead, and so on). issues in both documentary and fiction genres. Part way through the discussion, one of the students hesitantly says she doesn't understand why we are looking at issues of AIDS representation in a course on querying sex, gender and sexuality. I am surprised and ask if she can say more. She asks, what does AIDS have to do with gay men? I ask if other students also have this question and it turns out that she's not alone, many share some sense of not knowing what all this is about. In class, I attempt to offer some historical understanding. Afterwards, I am left gaping, shocked by the dissonance of a question that is reasonable for my students and largely unimaginable to me. What I get a glimpse of is how hard it is to keep the dead as a mattering, particularly when there is no personal relationship to sustain that bind, particularly when these dead are largely, still, disavowed.

Identity. Identification. Social bindings. Names. Matterings. Memories. Loss. Othering. Distance. Dehumanization. Violence. Indifference. Normativities.

\section{Generation?}

Words that tumble into my mind, out of my fingers, as I think on these two moments and what I/we may learn from their juxtaposition about "remembering queers and queering remembrances." For, in such naming, I am endeavouring to put into play 
two orientations at once: (i) to make a (partial) memorial archive of those who identify themselves or who are identified as "queers" (recognizing this is neither a stable nor coherent identificatory production); and, (ii) "to queer" the ways in which memorializing is thought, practiced, sustained, produced and lived. While the former project is more familiar to many, the latter may not be so easily encountered. Its significance lies for me in the kind of articulation that Donald Hall offers, in which "queering" is understood to "pose a particular threat to systems of classification that assert their timelessness and fixity." He continues: "It may not destroy such systems but it certainly presses upon them, torturing their lines of demarcation, pressuring their easy designations" (14). Hall has in mind systems of classification that produce and organize sexuality and desire; while these are obviously of interest in this special issue, so too are the classifications, demarcations and designations that produce and delimit contemporary thought on memorializing loss. Hence, you will read across these pages, for example, troublings of distinctions between history and memory (Stein), mourning and melancholia (Dickinson, J. Davidson), personal and collective trauma (Wright).

So who are the queers who are written into memory, onto these pages? Not surprisingly, but horrifyingly, you will again and again encounter the spectre of those gay men who have died from HIV/ AIDS. Indeed, there is barely a contribution to this special issue that does not either substantively feature memorialization of such men or mention these deaths as a haunting reminder. In an effort to recognize these losses as a particular kind, and not conflate them into equivalence with all other losses engaged across these pages, I have organized the scholarly articles into two parts: articles in Part A focus substantively on AIDS memorialization and politics; in Part $\mathrm{B}$, other losses and associated memorial practices are featured.

You will also encounter here some queers by name: Clive Boutilier (Stein goes on a search for this gay man deported from the U.S. in 1968) and Tom Waddell (Olympic medal winner and founder of the Gay Games, featured in J. Davidson's analysis). Other names are fictionalized, but come off the page as textured and nuanced figures (Bell introduces us to "Billy Vance" and Alley to "Arrowsmith"). Two of the contributors put themselves on the page as subjects of autobiographical consideration and inquiry (Wushke 


\section{4 / Rosenberg}

and Wright). Then there are the "queers" identified by broad category: lesbians and transgendered women at Toronto's Pussy Palace (Blair), sisters who dance for their dead brothers (Dickinson), gay games' athletes (J. Davidson).

If that snapshot offers some sense of the queers who are being remembered here, what characterizations of "memorial queer(y)ing" will you come upon? Dickinson poses one of the most difficult, but for that, pressing, demands of this collection: to queer who we think are "our brothers" in the wake of homophobic killings. That is, what he compels us to grapple with is that our identifications and extensions of care cannot only be to the gay and transgendered men who are murdered, as, he so pointedly puts it, by "straight men." He insists we must come to terms also with what it means that these killers too are "our brothers," part of the human in this time and place. Bride takes us in a different direction, asking us to consider the provocative possibility that cruising and gay public sex in the vicinity of an AIDS monument may be read not as "desecration" or "transgression" of what is normatively assumed to be sacred space, but as a particular, complicated practice of remembering. In the process, she queers dichotomies of life and death, grief and pleasure, present and past. Wright picks up on the complicated intertwinings of such terms (thought through the particular complexities of living with trauma), offering us a text that is both itself a memorial archiving of his life as a gay man and activist and a discussion of archiving Bear History for which he has been a leading American figure. What Wright brings to the fore, also, are questions of "generation" and how they press on us differently - particularly in relation to the AIDS pandemic and its legacies.

In the second section of scholarly articles, Stein opens precisely with such gestures to generational differences, especially in relation to the very notion of "queer" as both an identity marker and a way of approaching history. Stein troubles the norms of historical interpretation, relations between past(s) and present(s), and the status of "evidence," presenting us with a complicated, unstable-and for these reasons-exciting rendering, not only of his historical subject per se, but also of the very project of writing history queerly. J. Davidson reads history also - this time not from the perspective of an historian but through a psychoanalytic reading of the Gay Games and their memorial practices and associated attachments. Davidson 
queers both psychoanalytic and memorial readings in this analysis, asking us to consider the workings of psychic investments at an organizational (rather than singularly individual) level and their effects for loss, mourning and "moving on." What she poignantly calls our attention to is that memorial pride is complexly caught up in historical shame, queer(y)ing any simple dichotomy of these terms. Blair brings this section of the special issue to a close, by also focusing on loss - in this case a loss that was threatened but that did not occur when charges against the Pussy Palace organizers in Toronto were dismissed. Through an engaged reading of gay bathhouse literature, and a particular attention to a queer(y)ing of "sight" and "evidence," she speaks to the complex ways in which the loss that wasn't nevertheless animated a series of public responses to the Pussy Palace raids and its aftermath.

In the creative writing and local knowledge sections such queering of memorialization continues, with contributions from Alley and Bell, D. Davidson and Wushke respectively. Alley's beautiful and poignant story troubles facile distinctions between love, anger, loss and attachment, while Bell calls a queer and sharp attention to the utter inadequacy of academic institutions for what they cannot see and render, most awfully, unintelligible. D. Davidson's reflections too reveal traces of anger as she grapples with her own history of AIDS education, and particularly the practices of what I might call "memorial activism," as these are brought to the fore through her engagement with the AIDS Quilt. Wushke's hermeneutic / therapeutic engagement with a 1975 photograph gives us queered insight into the workings of interpretation (his own and those he imagines of others') as markers of gender and sexuality are read and reread for (new) understanding.

The particular queer(y)ing that I would like to offer, in part inspired by those authors have already shared with me, is concerned with the very pairing that is at the heart of this issue and its call for papers: namely, the pairing of practices of remembrance with practices of identity and identification. This is not an unusual binding in late modernity, rather it is exemplary (as we well know, for example, from Holocaust memorials to the monumentalization of Ground Zero). Nonetheless, it is, as scholars and practitioners of memory continuously point out, a binding that is apparently necessary (yet problematic), imperative to imagine ourselves away 


\section{6/Rosenberg}

from (yet difficult to do so). Indeed, I was particularly drawn to the idea of this special issue precisely because I felt that the notion of queer(y)ing might offer something in the way of opening up the complex and complicated ways that loss, identity, identification and memorializing are caught up with each other. On the one hand, I anticipated that a notion of queering would direct us away from commitments to and expectations of stabilized identity categories (as it has for a number of the authors featured here); on the other hand, what remains clear is that enactments of queer (as identity and/ or accusation) must continue to matter to the hows and whys of loss, indifference, death, violence, and the stakes of remembering. Grappling in the midst of this dilemma, I want to suggest that a queer(y)ing of memorialization (theory and practice) might alert us to a series of particular troubles that demand attention. Five in particular strike me.

First, we might ask after, as Judith Butler does, the limit of the name (or even an image) to conjure the dead. She enquires: "Do names really 'open' us to an intersubjective ground, or are they simply so many ruins which designate a history irrevocably lost? Do these names really signify for us the fullness of lives lost, or are they so many tokens of what we cannot know ...?" (Rev. 69). What Butler astutely captures for us here, I think, is the very complicated matter of naming the dead as a practice of remembering. On the one hand, such naming is crucial-not least in situations, for example, in which people are murdered as "nameless" representations of an identity category stained by hatred. Inscribing the name of the dead, designating them as individuals, may also be utterly crucial for those who are still the living, for whom the name works as an intersubjective and felt recall (I am reminded here of the woman who I observed passing the Vancouver AIDS Memorial). On the other hand, when the names do not mark for the living a previously known or loved person, they risk becoming not so distinct from the very unapproachable, untouchable, numbers that they are hoped to give embodied texture to. The question becomes, perhaps, when the names are listed under or as part of an assumed identity category (e.g., those who have died from AIDS), what kind of memorial relation is conjured between the living and the dead-particularly for those who do not have prior affective connections to these names? 
Following this thought, we might also be concerned by the ways in which identity categories bind the living to the dead on limited and delimiting terms; such that, in its broadest and most reductive brush, for example, living gays are assumed to have a particularly charged memorial relation to dead gays and those living who do not identify as gays are assumed to have a distant or less authentic or less binding relation to those dead (Stein offers us some thoughts here). On such terms, dichotomies tend to reign (victim vs perpetrator, gay vs straight, innocence vs evil), such that dead and living are singularized and regulated into $a$ priori categories that leave little room for grappling with how queerness, for example, is necessary and yet insufficient to facing loss, death and its lingering effects-for all, albeit differently (as Dickinson reminds us). Such issues are particularly charged when we start to think across "generations," as the living turn not to the dead who were known to us in life, or among whom we shared some sense of community, of being in a particular time and place, but toward a dead unknown to us-for whom we have come after, we were not born when they were living, they are no longer who we think of as "us" (Wright offers us some sense of this dissonance).

Third, attention might also be drawn to the ways in which practices of "collective" remembering in late modernity tend to be marked as the responsibility of specialized institutions (e.g., memorial museums) and specified dates (e.g., AIDS Remembrance Day), particularly in social formations that are oriented primarily by the forgetting "necessary" to progress (Gross). As Wendy Brown reminds us, "ours is a present hurtled into the future without regard for human attachments ... a present that dishonours the past by erasing it with unprecedented speed and indifference" (142). In the midst of such a hurtling present, we build monuments, museums, memorial walls and benches, in the hopes that they may slow down something of this time, such that what and who has been lost is given a presence, a marker, a place of mattering. And yet, as James Young has long reminded us, the risk is that such memorial practices become part of the landscape, memorial benches become just another park bench, "relieving us," in his words, "of the memory-burden we should be carrying" (127). The question then becomes how to engage such practices differently, such that they animate remembering rather than allow for a sense that the stakes of remembering are settled by stone 


\section{$8 /$ Rosenberg}

(or steel or cloth) repositories that will do the work of remembering for us (recognizing that "us" is a complicated evocation too).

Caught in the force of late modernity's speed and indifference, it is little wonder (but of deep concern) that identity comes to matter in rigid ways, with violent effects. As Butler again argues, in her more recent work, it is imperative to critically "evaluate and oppose the conditions under which certain human lives are [made] more... grievable than others" (Precarious 30). She suggests we must do this not out of some sense of moral righteousness, but because we are as much formed by those whom we grieve for socially and publicly, as by those whose deaths are disavowed because they are rendered less than human (46). While Butler is speaking specifically here to the twined avowals and disavowals of deaths in post $9 / 11$ America, her words resonate in the context of this special issue also. For, to take seriously her position is to reckon with how the deaths of queers not only press on, leave enduring marks of pain for living queers (where spatial and identicatory proximities may be closer), but also all of us. We see such extensions of mattering, for example, in the case of particularly horrific and made-public deaths-Mathew Shepard, Brandon Teena, Aaron Webster readily come to mind here. Yet this is not a general and guiding orientation-I note, for instance, that no papers were submitted to the call for papers on remembering the disappeared women in Vancouver (although mention is made in Dickinson), partly, I suspect, because for all of the ways in which some of us understand queer and queering as markers of troubling, they are not (still) readily read that way.

This points me toward the remaining risk in the fraught intertwinings of identity and identification, loss and memorializing: the complex relations between "mourning" and "activism." Largely still understood in a dichotomous relation (as the feminist call following the Montréal massacre exemplified, "first mourn, then work for change"), what's clear from the papers offered here is that these modes of being, these orientations to life and death, are far more intertwined than the dichotomy allows for. As Donald Crimp concluded years ago, what is necessary is "mourning and militancy" (149). And yet this "and" is not so easily rendered in daily practiceswhen the psychic demands of mourning and facing loss seem at odds with the relational and material demands of "acting up" for a different world (see J. Davidson for a particular take on this dilemma). In the 
mire of and between these pulls, there are risks that another demand is demanded: namely the demand of identity. That is, "to be" queer means "to remember queer" means to "act-up queer" in ways that may neither recognize nor help us to reckon with how grief, loss and sadness work-individually and in social formations. As Butler may prompt us to ask, in yet other deliberations on these matters (and as Blair and Bride pick up on), how might loss be constituted such that it is reckoned with as a necessary condition for community? (Afterword 468) How then might we imagine and realize a different relation between mourning and activism?

As my parenthetical gestures indicate, not each of these risks is featured in each of the papers that follow, nor could they be. Rather, specific risks become more and less tangible for authors as they endeavour to work with thought and passion, rigour and connection, in making meanings and offering us provocative deliberations on the doubled moment of remembering queers and queering remembrances. Working with each of the authors, reading across the papers brought together here, I am profoundly reminded that to remember those who have passed, to memorialize their loss, and to open the present to the demands of the dead are complex, complicated and enduring labours. To my mind, and as explicitly expressed on some of these pages, such labours are marked by and expressed through mutable intertwinings of thought, practice and affect, in which love tackles with grief, attachment with guilt, shame with pride. The journal issue you hold in your hands, finally, some two years in the making, is an expression of such labour-mine, but, more importantly, that of the contributors and those others (monument makers to judges, dancers to athletic organizations) who compel authors' thoughts to the page.

Working with these papers, I feel myself increasingly drawn to the idea that a particular care and attentiveness to the dead and their memorialization might be imperative to the possibilities for living otherwise than we have. Authors offer us different and not necessarily compatible characterizations of that care and attentiveness-and for that I am both grateful and excited. I hope you too will find here ideas, thoughts, naming practices, wonderings, contemplations, theorizings that touch your own in ways that may surprise, shock, open, and engage curiosity as we each grapple with what holds us here and draws us out toward what else there may be. 
As guest editor of this special issue, I extend my gratitude for the support, encouragement, patience and thoughtfulness of many people. My first thanks go to John Plews and Heather Zwicker, the editorial backbone of torquere. John was superb in his capacity as former editor, offering generous guidance and assistance particularly through the early stages of the process. Heather has been a wonderful source of support, encouragement and humour throughout and I am especially grateful for her astute proofing-eye! Kathryn Payne handled the creative writing contributions with care and Ellen Whiteman provided technical assistance when time was tight. My gratitude to the anonymous reviewers, each of whom gave timely and considered response. I especially offer my deep thanks to each of the authors whose work is featured here: for your patience, for your generosity of engagement with suggestions from myself and reviewers, and for the thoughts you have shared that have produced such an opportunity to think with and alongside you. I am also thankful for a course release, supported through a University of Alberta SAS Grant, which was partly used to help me bring this issue to completion. And, finally, my gratitude to J. for patiently loving me through the last months of producing this issue and for risking the big leap.

This issue would not have made it to production if it were not for the work, sense of responsibility, and careful attention of Bobby Noble and OmiSoore Dryden. My deep gratitude to them both and particularly for Bobby's hands-on attentiveness. If this is the last issue of torquere to be published, it is fitting that it be a memorial marker of what they have made possible from so many ruins.

Edmonton Spring 2005

\section{Works Cited}

Brown, Wendy. Politics out of History. Princeton: Princeton University Press, 2001.

Butler, Judith. "Afterword: After Loss, What Then?" Loss: The Politics of Mourning. Eds. David L. Eng and David Kazanjian. Berkeley: University of California Press, 2003. 467-473.

- Precarious Life: The Powers of Violence and Mourning. New York and London: Verso, 2004. 
Rev. of Spirit in Ashes, by Edith Wyschogrod. History and Theory 27.1 (1988): 60-70.

Crimp, Donald. "Mourning and Militancy." Melancholia and Moralism: Essays on AIDS and Queer Politics. Cambridge and London: MIT Press, 1989. 129-149.

Hall, Donald E.. "Introduction.” Queer Theories. New York: Palgrave MacMillan, 2003. 12-16.

Gross, David. Lost Time: On Remembering and Forgetting in Late Modern Culture. Amherst: University of Massachusetts Press, 2000.

Young, James. The Texture of Memory. New Haven and London: Yale University Press, 1993. 